\title{
Intracardiac Repair in Adult Tetralogy of Fallots with Destroyed Lung (Post Tubercular)
}

\author{
Jaideep Kumar Trivedi*, GV Raman Kumar², K Damodar Rao ${ }^{3}$, P Ravi Chandrahas ${ }^{4}$, Kiran Tanety ${ }^{4}$ and K Rama Rao ${ }^{4}$ \\ ${ }^{1}$ Department of Cardiothoracic Surgery, Apollo Hospitals, Vishakhapatnam, India \\ ${ }^{2}$ Department of Cardiothoracic Surgery, My Cure Hospitals, Vishakhapatnam, India \\ ${ }^{3}$ Department of Interventional Cardiology, My Cure Hospitals, Vishakhapatnam, India \\ ${ }^{4}$ Department of Anaesthetiology, My Cure Hospitals, Vishakhapatnam, India
}

\begin{abstract}
Tetralogy of Fallots' (TOF) is the commonest cyanotic congenital heart disease. In this modern era when we are doing minimally invasive cardiac surgeries (MICS) and Robotic surgeries it is quiet uncommon to see a tetralogypresenting at the age of 42 years for intra cardiac repair (ICR). We are reporting a case of adult TOF with destroyed lung (post tubercular) who presented to us with severe breathlessness. We did intracardiac repair and successfully managed the case.

Tetralogy of Fallots presenting at 42 years is relatively uncommon. TOF with destroyed lung is again a rarity. By our case report we want to give message to surgeons and cardiologist that TOF can present with tuberculosis and destroyed lung at this stage also and can be operated and successfully managed and will be benefited by surgery.
\end{abstract}

Keywords: Congenital; Mycobacterium tuberculosis; Heart disease; Surgery

\section{Introduction}

Tetralogy of Fallot (TOF) is the commonest cyanotic congenital heart disease. When we see the natural history of TOF only two third cases survive up to 1 st birthday, $50 \%$ survive up to 3 years, $25 \%$ up to 10 years and only $3 \%$ are alive at 40 years. Tuberculosis is rarely seen in TOF. Children with a cyanotic heart disease (atrial septal defect, ventricular septal defect, patent ductus arteriosus) are more prone for tuberculosis whereas low oxygen concentration in TOF is not favourable for the growth of Mycobacterium tuberculosis.

\section{Case Presentation}

We report a rare case of tetralogy of fallots in an adult with destroyed lung as a sequel of old pulmonary tuberculosis. 42 year male presented to us with severe breathlessness of grade 3 to 4 . On examination he had cyanosis, clubbing and saturation of $85 \%$ on pulse oxymeter. On auscultation air entry was almost absent on left side and 2-3/6 systolic ejection murmur was present on cardiac examination. Abdominal examination was normal. He was a diagnosed case of TOF with history of tuberculosis 20 years back for which he took antitubercular treatment for 1 year. His $\mathrm{x}$-ray was suggestive of destroyed left lung and changes of old tuberculosis (Figure 1). His montoux test was positive and sputum for AFB (acid fast bacilli) negative. Trans-thoracic and trans-esophageal echocardiographic study revealed classic findings of tetralogy of Fallot (TOF) (pulmonary valve stenosis, right ventricular hypertrophy and enlargement, large ventriculer septal defect with an overriding aorta). We did his cath study which revealed normal coronaries, no anomalous coronary artery crossing right ventricular outflow tract, no aortic regurgitation and no major aorto-pulmonary collaterals. Intacardiac repair was done. Intra operative findings were there was thickened pericardium which was densely adherent to heart, left side pleura was thickened and totally stuck, large subaortic vsd (ventricular septal defect) was closed by PTFE(polytetra fluro ethylene) patch using 5-0 prolene interrupted sutures and pulmonary valve was thickened and bicuspid. Pulmonary valvotomy was done and NO.20 size hegar was passed through RVOT (Figure 2), and was closed with pericardial patch. Patient was ventilated for $48 \mathrm{hrs}$, extubated on 3rd post op day and was kept on intermittent Bipap ventilation for 3 days. He remained

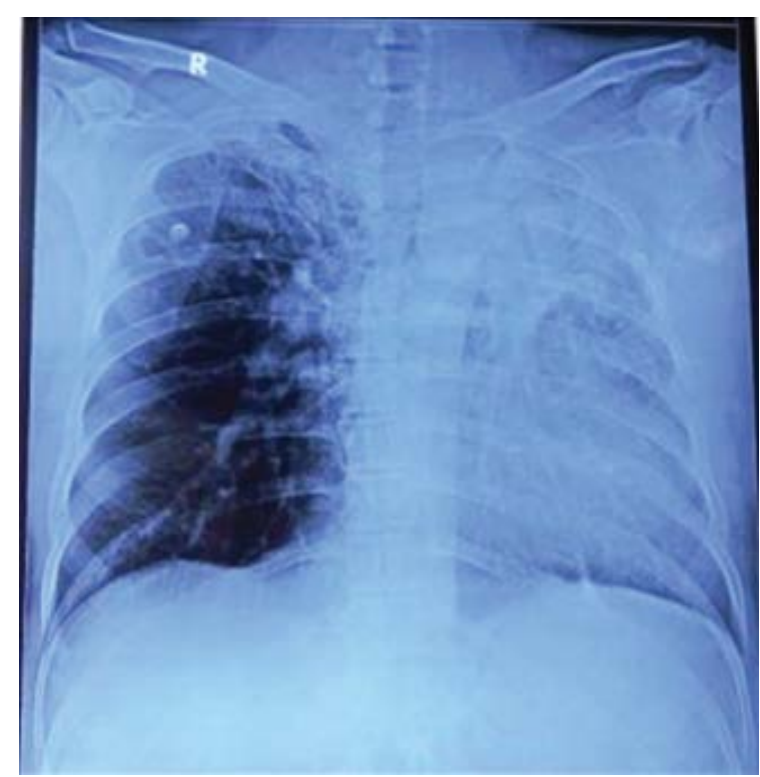

Figure 1: X-ray chest showing left sided destroyed lung.

haemodynamically stable, arterial blood gases improved and post op recovery was uneventful. In post op echo there was no residual vsd, mild gradient across RVOT and good biventricular function. Patient is following up with us since last one year and is asymptomatic. His chest $\mathrm{x}$-ray also improved on left side with better lung expansion (Figure 3).

*Corresponding author: Dr. Jaideep Kumar Trivedi, Department of Cardiothoracic Surgery, Apollo Hospitals, Health City, Arilova, Vishakhapatnam 530040, Andhra Pradesh, India, Tel: 91-8712245666/9827124443; E-mail: drjdtrivedi@yahoo.co.in

Received June 12, 2017; Accepted June 25, 2017; Published July 02, 2017

Citation: Trivedi JK, GV Raman Kumar, K Damodar Rao, P Ravi Chandrahas, Tanety K, et al. (2017) Intracardiac Repair in Adult Tetralogy of Fallots with Destroyed Lung (Post Tubercular). Surgery Curr Res 7: 297. doi: 10.4172/2161-1076.1000297

Copyright: @ 2017 Trivedi JK, et al. This is an open-access article distributed under the terms of the Creative Commons Attribution License, which permits unrestricted use, distribution, and reproduction in any medium, provided the original author and source are credited. 
Citation: Trivedi JK, GV Raman Kumar, K Damodar Rao, P Ravi Chandrahas, Tanety K, et al. (2017) Intracardiac Repair in Adult Tetralogy of Fallots with Destroyed Lung (Post Tubercular). Surgery Curr Res 7: 297. doi: 10.4172/2161-1076.1000297

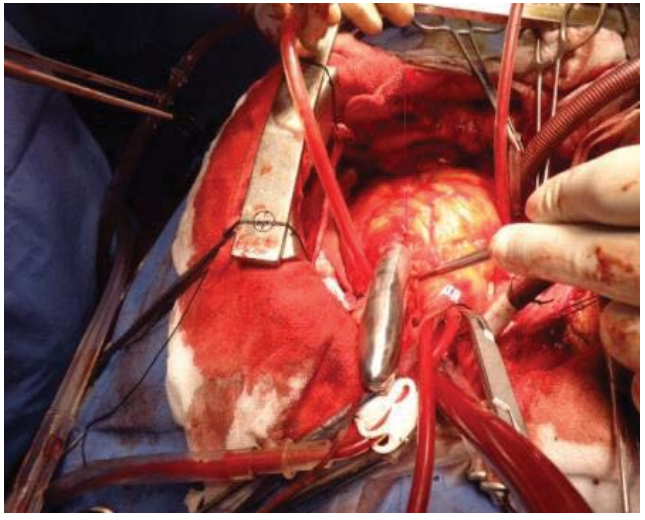

Figure 2: Intraop picture showing pulmonary valvotomy and hegar dilator.

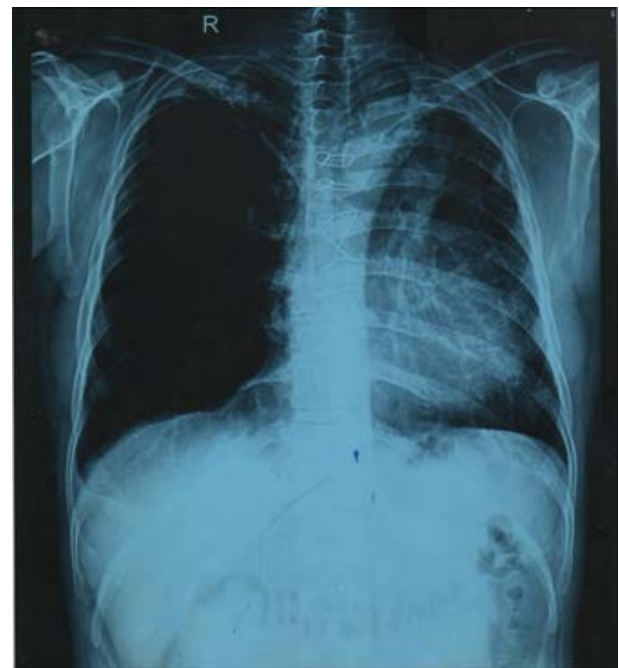

Figure 3: Post ICR X-ray showing better expanded lungs on left side.

\section{Discussion}

Tetralogy presenting after 40years of age is relatively uncommon and surgery in adult TOF is very challenging. Late presentation and long standing cyanosis leads to myocardial fibrosis and RV dysfunction. Dysrhythmias are very common in this age group. Coagulation defects results in lot of blood loss and plenty of requirement of blood and blood products. Compromised lungs in this case makes surgery more complicated and difficult to manage. Congenital heart diseases are divided into two groups; cyanotic-CHD and acyanotic-CHD. Van der Merwe et al. [1] reported that patients with acyanotic-CHD (increased or normal pulmonary blood flow) are susceptible to develop pulmonary TB. However, pulmonary TB was rarely reported in patients with TOF which is a cyanotic-CHD with decreased pulmonary blood flow [1,2]. Van der Merwe et al. [1] explained this situation as reduced pulmonary blood flow and cyanosis in patients with cyanotic-CHD can inhibit growth of $M$. tuberculosis whereas increased pulmonary blood flow and normal pulmonary arterial saturation in patients with acyanotic-CHD can provide a suitable environment to growth. Thus tuberculosis and TOF rarely coexist $[3,4]$.

\section{Conclusion}

Tetralogy of Fallots presenting at 42years is quiet uncommon nowadays. TOF with destroyed lung again a rarity. By our case report we want to give message to surgeons and cardiologist that TOF can present with tuberculosis and destroyed lung at this stage also and can be operated and successfully managed and will be benefited by surgery.

\section{References}

1. van der Merwe PL, Kalis N, Schaaf HS, Nel EH, Gie RP (1995) Risk of pulmonary tuberculosis in children with congenital heart disease. Pediatr Cardiol 16: 172-175.

2. Radović M, Ristić L, Stanković I, Petrović D (2010) Rare congenital heart disease as a cause of tuberculosis activation. Med Pregl 63: 565-569.

3. Abraham KA, Cherian G, Rao VD, Sukumar IP, Krishnaswami S, et al. (1979) Tetralogy of Fallot in adults. A report on 147 patients. Am J Med 66: 811-816.

4. Murthy JS, Abraham KA, Rajagopal S, Sudarsana K, Somanath HS (1995) Tetralogy of Fallot in adults--107 cases. J Assoc Physicians India 43: 25-27. 